\title{
Paraneoplastic syndromes in small cell lung cancer
}

\author{
Zaid Soomro ${ }^{1}$, Michael Youssef ${ }^{1}$, Shlomit Yust-Katz ${ }^{2}$, Ali Jalali ${ }^{3}$, Akash J. Patel $^{3}$, Jacob Mandel $^{4}$ \\ ${ }^{1}$ University of Texas MD Anderson Cancer Center, Houston, TX, USA; ${ }^{2}$ Rabin Medical Center, Petach Tikva, Israel; ${ }^{3}$ Department of Neurosurgery, \\ ${ }^{4}$ Department of Neurology, Baylor College of Medicine, Houston, TX, USA \\ Contributions: (I) Conception and design: None; (II) Administrative support: None; (III) Provision of study materials or patients: None; (IV) \\ Collection and assembly of data: Z Soomro, M Youssef; (V) Data analysis and interpretation: None; (VI) Manuscript writing: All authors; (VII) Final \\ approval of manuscript: All authors. \\ Correspondence to: Jacob Mandel, MD. Department of Neurology, Baylor College of Medicine, 7200 Cambridge St, Suite 9A, Houston, TX 77030, \\ USA. Email: Jacob.mandel@bcm.edu.
}

\begin{abstract}
Paraneoplastic syndromes can commonly occur due to lung cancer, especially small cell lung cancer. Frequently paraneoplastic syndromes can precede the diagnosis of the neoplasm or present with limited stage disease. However, these syndromes can also occur at the time of recurrence or metastasis of disease. This review focuses on the epidemiology, pathogenesis, clinical features, and current management of the most common paraneoplastic syndromes encountered in patients with small cell lung cancer. Manifestations of paraneoplastic syndromes in small cell lung cancer include endocrine syndromes with secretion of excess hormones, and neurologic syndromes due to the production of antibodies causing an autoimmune condition. Recent advances have allowed for greater understanding of these syndromes and for the development of improved diagnostic as well as therapeutic tools. Awareness of paraneoplastic syndromes in small cell lung cancer can lead to an earlier diagnosis and recognition of both the condition and in some cases the disease potentially improving the overall survival and prognosis for patients. Further research examining effective methods to improve recovery from neurologic deficits in patients with a paraneoplastic neurologic illness is warranted.
\end{abstract}

Keywords: Paraneoplastic syndrome; small cell lung cancer (SCLC); paraneoplastic endocrine syndromes; paraneoplastic neurologic syndromes

Submitted Feb 24, 2020. Accepted for publication Mar 11, 2020.

doi: $10.21037 /$ jtd.2020.03.88

View this article at: http://dx.doi.org/10.21037/jtd.2020.03.88

\section{Introduction}

The term paraneoplastic syndrome was first used in the literature in 1940 to describe the poorly understood phenomena in which patients were observed to experience a series of similar signs and symptoms in association with the presence of certain cancers (1). With the progress of basic science research and advances made in clinical medicine, we now have a more sophisticated understanding of what causes paraneoplastic syndromes, the many ways in which they can present clinically, how to categorize them, their associations with different pathologies and effective strategies to diagnose and manage them. A notable example of this process of discovery and advances in the understanding of paraneoplastic syndromes is the detection of the first antibody that targeted neuronal tissue that could be used clinically to diagnose paraneoplastic syndromes (2). In 1985, the anti-Hu antibody was discovered, correlating the clinical findings to an autoimmune etiology with the patients underlying cancer diagnosis. This finding allowed for the development of a new category of disease to clinically define certain neurological complications that present in cancer patients that are not able to be attributed to the primary tumor, metastases, metabolic, infectious, and vascular or treatment-related causes. After discovery of the anti-Hu antibody, the presence of several other antibodies in the serum and cerebrospinal fluid have been identified and associated with different paraneoplastic syndromes. In many cases, the association of 
the paraneoplastic syndrome and specific malignancies have now also been established $(2,3)$. Since many paraneoplastic syndromes are known to manifest clinically, before signs and symptoms of the primary malignancy, this has provided a clinical opportunity to potentially enable an early diagnosis of cancer in many patients (4).

Paraneoplastic syndromes are now understood to be a heterogeneous group of clinical syndromes characterized by a recognizable constellation of signs and symptoms in a patient that occurs in association with neoplastic disease processes. It is essential to distinguish that these clinical findings found in paraneoplastic syndromes are caused by primary tumors from a distant site and do not involve the primary tumor causing tissue damage through direct invasion, compression, or metastases $(5,6)$. Generally, the pathophysiology that causes the paraneoplastic syndromes involves the ectopic production of biologically active hormones or peptides by the primary tumor, or alternatively by immune-mediated processes, including antibody and cell-mediated mechanisms. Cross-reactivity between tumor antigens and normal host tissue is responsible for the disease processes seen commonly in paraneoplastic syndromes that produce damage by tissue-specific biologically active hormones or peptides (2). Paraneoplastic syndromes can be categorized according to the systems in which they provide the disease process (endocrine, neurologic, dermatologic, rheumatologic, immunologic, hematologic, and nonspecific).

An estimated $1-7.4 \%$ of patients with cancer will develop a paraneoplastic syndrome (7). The most common disease associated with paraneoplastic syndromes is lung cancer, with small cell lung cancer (SCLC) the most frequent subtype (7). Lung cancers are a leading global cause of morbidity and mortality accounting for an estimated $23.5 \%$ of all cancer deaths in the United States in 2019 (8). Paraneoplastic syndromes in patients with lung cancers typically involve the endocrine, neurologic, dermatologic, and rheumatologic functions (2). Less common manifestations include paraneoplastic hematologic syndromes (including coagulopathy), paraneoplastic ophthalmologic syndromes, and paraneoplastic glomerulopathy. Paraneoplastic syndromes that present in association with lung cancer can also be specific to the histology of lung cancer. An example of this phenomenon is that the squamous cell histological subtype of lung cancer is found in association with the paraneoplastic endocrine syndrome of hypercalcemia, mostly caused by the protein parathyroid hormone-related peptide (PTHrP). Similarly, SCLC is found in association with the paraneoplastic endocrine syndrome of syndrome of inappropriate antidiuretic hormone (SIADH), which is caused by the excessive ectopic production of antidiuretic hormone (ADH) (9-11).

SCLC is diagnosed in approximately 30,000 people each year and compromises an estimated $14 \%$ of all lung cancer cases diagnosed in the United States. Compared to the different types of lung cancers, SCLC is noteworthy due to its rapid rate of cellular proliferation, short doubling time, and propensity to metastasize early in the natural history of the disease. Most patients present in the advanced stages of the disease, and an estimated $90 \%$ of patients will have metastatic disease at the time of diagnosis (11). SCLC is a unique histologic subtype of lung cancer characterized by cells that have a neuroendocrine differentiation. Cells of a neuroendocrine origin often produce biologically active substances. The histologic nature of these malignant cells plays a role in producing paraneoplastic syndromes and the most common paraneoplastic phenomena in SCLC are SIADH and Lambert-Eaton myasthenic syndrome (LEMS) (7).

\section{Challenges of diagnosing SCLC and opportunities of paraneoplastic neurologic syndromes for early diagnosis}

An understanding of the paraneoplastic syndromes found in association with different cancers can provide an opportunity for early diagnosis and intervention. The challenge with this paradigm exists because patients can present with a wide range of clinical presentations. The signs and symptoms manifested by paraneoplastic syndromes can often seem to be unrelated to the symptoms commonly observed in patients with SCLC, such as hemoptysis and dyspnea $(12,13)$. Additional challenges are present in using paraneoplastic syndromes to raise suspicion for and establish diagnosis for a primary malignancy because paraneoplastic syndromes can present in association with more than one type of underlying malignancy and with varying frequencies (13-15). Specific paraneoplastic syndromes can exist both as a unique primary disease entity and as paraneoplastic syndrome secondary to a malignant disease process. These seemingly related diseases are clinically similar but have different etiologies and exist as their unique disease entities. An example of this phenomenon is that of Cushing's disease and Cushing's syndrome $(16,17)$.

It is essential to understand why SCLC is often diagnosed when the disease has reached an advanced stage. The delay in time between when the disease initiates in the lungs to when the symptoms first appear and SCLC is first diagnosed, is caused by the central anatomic location of the lungs in 
Table 1 Paraneoplastic neuroendocrine syndromes

\begin{tabular}{|c|c|c|c|}
\hline Syndrome & Presentation & Lab findings & Treatment options \\
\hline SIADH & $\begin{array}{l}\text { Falls, headache, nausea, fatigue, } \\
\text { muscle cramps, seizures, lethargy, } \\
\text { tremors, depressed mood }\end{array}$ & & Hypertonic saline \\
\hline
\end{tabular}

SIADH, syndrome of inappropriate antidiuretic hormone; ACTH, adrenocorticotropic hormone.

the thoracic cavity. By the time SCLC is diagnosed, patients are in the advanced stages (Stages 3 and 4) of disease. Unfortunately, these patients have low rates of survival and face a very poor prognosis even with treatment. The presence and early identification of paraneoplastic syndromes can be beneficial in this context. A survival advantage has been demonstrated for patients that are diagnosed early at Stage 1a and received surgical resection (18). Patients with SCLC with paraneoplastic syndromes can present at an early stage of the disease (19), and offer an opportunity for the early diagnosis and early intervention leading to improved survival outcomes for patients with SCLC.

This review will provide an essential overview of the paraneoplastic syndromes that are most often associated with SCLC. Specifically, we will focus on discussing the most common types of paraneoplastic endocrine syndromes and paraneoplastic neurologic syndromes observed in SCLC patients. The literature that was reviewed to prepare this article was searched on PubMed and Google Scholar in February 2020. The search terms used to conduct the literature search were "Paraneoplastic" and "Small Cell Lung Cancer", with the use of the Boolean, "AND" when searching the Medline database of literature through PubMed. We also used the "Best Match" feature in PubMed. The most relevant articles on our topic were selected for review The criterion used to choose most of the articles included in no specific order of priority; relevance to subject matter, number of times the article was cited, impact factor and journals that were published by major professional and academic medical societies.

\section{Paraneoplastic neuroendocrine syndromes}

SCLC is composed of neuroendocrine cells and a characteristic of these cell types is their propensity to produce biologically active substances (12). SCLC is often responsible for the production of ectopic hormones that the body typically produces as part of its normal physiology. This can manifest in several different clinical syndromes, including SIADH, ectopic Cushing's syndrome, humoral hypercalcemia of malignancy, and acromegaly (13). Here we will discuss the two most common neuroendocrine paraneoplastic syndromes related to SCLC, SIADH and ectopic Cushing's syndrome. Table 1 describes basic features of SIADH and ectopic Cushing's syndrome.

\section{Syndrome of inappropriate antidiuretic hormone}

SIADH is the most common paraneoplastic endocrine syndrome associated with SCLC. It is defined as a hyponatremia associated with increased renal water retention, with plasma sodium level less than $134 \mathrm{mmol} / \mathrm{L}$, plasma osmolality less than $275 \mathrm{mOsm} / \mathrm{L}$, urine sodium level more than $20 \mathrm{mmol} / \mathrm{L}$, urine osmolality greater than the plasma osmolality, absences of edema or volume depletion, and normal renal and adrenal function (15). SIADH in relation to SCLC was first reported in the literature in 1957 and described in two lung cancer patients with hyponatremia and excess renal sodium (14). Further work in 1968 discovered the role of ADH in SIADH (17). $10-45 \%$ of patients with SCLC will develop SIADH at some point during their illness with production of $\mathrm{ADH}$ in an unregulated manner leading to hyponatremia, hypoosmolality, increased urine sodium excretion, and a high urine osmolality relative to the tonicity of the plasma $(10,11,16,20)$. As $\mathrm{ADH}$ is secreted in excess, there is persistent action at $\mathrm{V} 2$ receptors in renal tubules, which results in increased expression of aquaporins and causes water retention by reabsorption. The clinical diagnosis of SIADH depends on the assessment of the patient's 
intravascular volume status as well as laboratory findings that support this diagnosis.

Management of SIADH secondary to a paraneoplastic syndrome involves treatment of the underlying tumor through surgical resection, chemotherapy, radiation, or a combination of the above (20). SIADH-induced hyponatremia can require free water restriction to one liter or less per day for asymptomatic mild hyponatremia or with the administration of hypertonic $3 \%$ saline in life-threatening or symptomatic hyponatremia (13). Other treatments for hyponatremia include the antibiotic demeclocycline and the vasopressin receptor antagonists, which must be used with caution to avoid over-correction of hyponatremia. It is also advised that patients obtain an adequate intake of dietary sodium and protein to maintain a euvolemic, eunatremic status (21). The rate of correction must also be considered, as to prevent neurologic deficit such as osmotic demyelination. In patients with acute onset hyponatremia, correction of $1-2 \mathrm{mmol} / \mathrm{L} / \mathrm{h}$ is safe and adequate. In patients with chronic hyponatremia, the rate of correction should be $0.5-1 \mathrm{mmol} / \mathrm{L} / \mathrm{h}$ without exceeding $10-12 \mathrm{mEq}$ in the first twenty-four hours (22-24).

\section{Ectopic Cushing's syndrome (ECS)}

The second most common paraneoplastic syndrome occurring with SCLC is ECS, occurring in $1-5 \%$ of cases $(25,26)$. Fifty percent of the cases of ectopic Cushing's syndrome are related to lung tumors with $8-20 \%$ associated with SCLC (27). When ECS is associated with SCLC, there is a poorer prognosis because of advanced stage, inadequate response to therapy, and increased complications related to their diseases, such as infection and venous thrombosis. Patients with Cushing's syndrome typically present with weight gain; however, $10 \%$ of patients with ECS related to SCLC presented with weight loss (27). Other clinical features can resemble Cushing's syndrome, including moon facies, acne, purple striae, proximal muscle weakness, peripheral edema, hypertension, and metabolic alkalosis with hypokalemia, the latter of which is detected in the majority of patients with Cushing's syndrome. This condition was first described in the literature in 1928 and further reports in the modern era remained consistent that this disease entity differed from Cushing's syndrome in that it did not elicit the classic signs of Cushing's syndrome $(9,28)$. It was also found that ECS could develop during effective chemotherapy for SCLC
(29). Diagnosis of ECS consists of complete imaging evaluation with contrast-enhanced CT scan of the chest, abdomen, and pelvis, plasma adrenocorticotropic hormone (ACTH) concentration greater than $15 \mathrm{pg} /$ $\mathrm{mL}$, non-suppressed morning cortisol level after highdose dexamethasone suppression test, elevated 24-hour urine-free cortisol level, and sampling of tissue, if found on CT scan. Several studies have suggested that systemic chemotherapy achieves more prolonged survival (30-33). Other medications, including etomidate, mitotane, ketoconazole, metyrapone, and mifepristone are used to reduce circulating glucocorticoids (34). Of these medications, ketoconazole was the first accepted treatment in 1985 due to patient tolerance even though there are moderate toxicities, given its status as a cytochrome $\mathrm{P} 450$ inhibitor (35). In severe cases, these medications are used in combination to reduce the amount of circulating cortisol. Systemic chemotherapy, however, remains the backbone of treatment. Patients with ECS have an increased susceptibility for venous thromboembolism (VTE) and opportunistic infection after treatment due to chemotherapy exposure (36-38). ECS patients with VTE have been shown to have elevated levels of coagulation factors II, V, VIII, IX, XI, and XII resulting in a net increased risk of $2 \%$ of thrombosis in patients who do not undergo surgery, and $4 \%$ increased risk in those who do undergo surgery $(39,40)$. Overall, lowering a patient's cortisol level prior to curative treatment was found to reduce a patient's morbidity and mortality associated with Cushing's syndrome.

\section{Paraneoplastic neurologic syndromes (PNS)}

PNS are a heterogeneous group of neurological disorders caused by indirect and remote effects of the primary tumors. They are a relatively rare group of diseases found in less than $1 \%$ of all patients diagnosed with cancer. SCLC is the most common diagnosis associated with PNS. An estimated $3-5 \%$ of cases of SCLC will have comorbid PNS. The disease processes that produce the PNS can occur at one or more sites in the nervous system, ranging from the central nervous system, peripheral nervous system, neuromuscular junction, and muscle. The PNS are typically characterized clinically as having a subacute, progressive disease course.

A diagnostic criterion has been used to classify the different types of PNS presentations as "Definite PNS" and "Possible PNS" (41). Patients will often present with neurological complaints first rather than classical symptoms 
Table 2 Neurologic paraneoplastic syndromes associated with small cell lung cancer

\begin{tabular}{|c|c|c|c|c|}
\hline Antibody & Cellular location & Conditions found & Diagnostic value & Titer predictive? \\
\hline$P / Q$ channels & $\begin{array}{l}\text { Presynaptic } \\
\text { neuromuscular junction }\end{array}$ & Lambert Eaton syndrome & Yes & No \\
\hline
\end{tabular}

of SCLC. Recognition of PNS in patients should raise possibility of an underlying malignancy. It is important to remember that clinical syndromes similar to paraneoplastic syndromes are not always secondary to a neoplastic disease process. Limbic encephalitis and subacute sensory neuropathy is caused by a non-neoplastic disease process in $70 \%$ of cases (42). A diagnosis of PNS requires ruling out the non-neoplastic pathologies, and this warrants an extensive diagnostic workup to detect the malignant disease. This workup can include testing for different antibodies, performing imaging studies, neurophysiological tests such as electroencephalography, electromyography, nerve conduction studies and cerebrospinal fluid analysis (43),

The mechanisms for the development of these paraneoplastic syndromes are not well understood, but they are known to be caused by an autoimmune-mediated disease process (44). These antibodies, often known as "onconeural antibodies" are frequently detected in the serum and cerebrospinal fluid and are characteristic of PNS (45). The immunologic phenomenon of cross-reactivity is involved in the activity of the onconeural antibodies. These antibodies are formed in response to tumor antigens that can be located on either the surface of neuronal tissue or intracellular neuronal antigens. The formation of antibodies specific to intracellular neuronal antigens is thought to involve cellmediated immune mechanisms.

Onconeural antibodies bind to antigens on normal host neuronal tissues that share epitopes with the tumor antigens. Onconeural antibodies produced in PNS patients can be directed towards surface antigens or intracellular neuronal antigens. Onconeural antigen-specific T-cells are also thought to be involved in the pathogenesis of PNS (18). These autoimmune mechanisms lead to damage in neuronal tissue in the CNS. The specific constellation of each PNS depends on the site, extent, and duration of disease involvement (46).

As mentioned previously, PNS is often found in association with SCLC and can cause severe disability in patients. The most common PNS found in patients with SCLC is LEMS. It is estimated to be present in about $1-3 \%$ of patients with SCLC (47). A single region prospective study conducted in the United Kingdom on 264 patients with biopsy-proven SCLC had estimated the disease frequency of PNS much higher than expected at 9.4\% suggesting that PNS could be underdiagnosed in patients with SCLC. According to the results of the same study, the most frequent type of PNS diagnosed in patients with SCLC was LEMS (3.8\%), sensory neuropathy (1.9\%) and limbic encephalitis (1.9\%) (44). As discussed prior, it is essential to be aware of these common paraneoplastic syndromes because their presence can raise suspicion of an underlying cancer (42).

Early cancer and immunosuppressive treatments in PNS are recommended to get rid of the antigen source and lower the immune response. These therapeutics can be of potential benefit if started promptly in patients, however the chance of responding varies depending on the paraneoplastic syndrome. Syndromes with antibodies against the neuronal cell surface or synaptic proteins that are antibody facilitated tend to respond better than paraneoplastic disorders with antibodies against intracellular antigens (classical paraneoplastic or onconeural antibodies) that are thought to act via a cytotoxic T cell mediated process. Table 2 describes the most common antibodies involved in PNS, conditions where the antibodies are found, and the predictive nature of the titers when tested.

\section{Lambert-Eaton myasthenic syndrome (LEMS)}

LEMS is the most diagnosed PNS associated with SCLC. Patients diagnosed with LEMS present with progressively worsening lower extremity weakness, diminished or absent deep tendon reflexes and constitutional symptoms, most often fatigue that characteristically improves with facilitation. Cranial nerve involvement can rarely occur 
and typically presents as blurred vision, diplopia, and ptosis. Autonomic nervous system involvement can lead to symptoms of dry mouth and constipation. Severe cases of LEMS can also have a respiratory weakness (48). LEMS is diagnosed based on the clinical presentation of the patient, electrophysiologic findings including decreased compound muscle action potential, decremental repetitive nerve stimulation at low frequency with increment $>100 \%$ at maximum voluntary contraction or high frequency (49).

LEMS is caused by onconeural antibodies that bind to (P/ Q) type voltage-gated calcium channels. These antibodies are typically found on the surface of presynaptic nerve terminals at the neuromuscular junction and the primary tumor (50). The pathophysiology of LEMS involves the binding of these antibodies to (P/Q) type voltage-gated calcium channels. Typically, these channels release calcium in the presynaptic nerve terminal of the neuromuscular junction in response to an action potential. The release of calcium causes the vesicle containing the neurotransmitter acetylcholine to release its contents from the presynaptic nerve terminal into the synaptic cleft. The onconeural antibodies associated with LEMS bind to the (P/Q) type voltage-gated calcium channels on the presynaptic nerve terminals and disrupt the normal function of the neuromuscular junction, and titer levels can be measured, however they are not predictive of level of disability or response to therapy (48). The motor weakness of LEMS can be improved with 3,4-diaminopyridine, cholinesterase inhibitors, and immunosuppressive therapy including glucocorticoids, intravenous immunoglobulin (IVIG), and plasma exchange, however guidelines for using IVIG and plasma exchange have yet to be proposed. Additionally, chemotherapy targeting the underlying malignancy is likely to ameliorate the clinical course of paraneoplastic LEMS (51).

\section{Myasthenia gravis}

Myasthenia gravis is a PNS that is found in association with SCLC and thymoma in approximately $15 \%$ of patients. The disease process is characterized and caused by the presence of the onconeural antibodies, anti-acetylcholine antibodies (anti-Ach) that act at the level of the neuromuscular junction. These antibodies bind to acetylcholine receptors (anti-AchR) located on the postsynaptic nerve terminals in the neuromuscular junction (4). This process leads to the competitive inhibition of the receptors and prevents the molecules of acetylcholine from binding. This leads to the disruption of action potential propagation in the postsynaptic nerve terminals leading to impaired muscle contraction.

Clinically it presents as patients that will complain of fatigue and muscle weakness involving voluntary and involuntary muscle groups. The muscle weakness becomes worse through the course of the day and with repeated activity. This weakness is especially pronounced in the proximal muscles of the limbs. Ocular and bulbar involvement can also present more commonly than with LEMS. Involvement of the diaphragmatic muscles is present in severe cases of myasthenia gravis (4).

Electromyography can be used to establish a definitive diagnosis of myasthenia gravis. If the disease is present, there will be a decremental response to repetitive nerve stimulation (4).

Symptomatic treatment for myasthenia gravis can be provided with the use of acetylcholinesterase inhibitors such as pyridostigmine, the inhibition of acetylcholinesterase, an enzyme that prevents the degradation of acetylcholine. This results in increased levels of acetylcholine, available to overcome the competitive blockade caused by the antiAch antibodies. Titer levels to the binding, blocking, and modulating acetylcholine receptor antibodies are measured for diagnosis and titers can be obtained, however the levels are not indicative of level of disability or response to therapy. Immunosuppressive therapies are also used to inhibit the underlying disease process and prevent the production of the antibodies. Thymectomy can be offered to patients that have myasthenia gravis with comorbid thymoma (4).

\section{Limbic encephalitis (LE)}

LE is a PNS that is one specific entity of a more generalized disease process called paraneoplastic encephalomyelitis. The different disease entities in paraneoplastic encephalomyelitis share a common pathological process causing the PNS but are different in the site of disease involvement. They are characterized by site-specific inflammation and neuronal loss (46). There is a strong association between paraneoplastic encephalomyelitis and SCLC. In patients with paraneoplastic encephalomyelitis there is a $75 \%$ chance that the underlying malignancy is SCLC. It is estimated that $40-50 \%$ of patients with LE have SCLC and $20-30 \%$ of patients have a testicular malignancy (52).

LE presents as an acute or subacute clinical syndrome. Patients with LE present with neuropsychiatric symptoms, anterograde amnesia, mood changes, hallucinations 
and seizures. Patients with LE have detectable levels of multiple onconeural antibodies, including anti-Hu, antiMa2 and anti-CRMP5 (52). The most common are anti$\mathrm{Hu}$ antibodies. The type of antibodies detected in LE can indicate the type of underlying malignancy. Anti$\mathrm{Hu}$ antibodies are typically associated with the presence of SCLC and anti-Ma2 antibodies are associated with testicular cancer. The diagnostic workup of LE involves electroencephalograms, FDG-PET, and MRI. If the LE disease process is established then these diagnostic tests all indicate the presence of specific findings that localize the pathological process localized to the temporal lobes (53). The onconeural antibodies are usually present at detectable levels in the serum. In instances when LE is suspected and there are no detectable antibodies in the serum, there is evidence of detecting antibodies in the cerebrospinal fluid to establish the diagnosis. Titers of the anti-Hu antibody can be obtained for diagnosis, but levels do not predict response to therapy or degree of disability. Since LE is caused by tissue damage due to onconeural antibodies, the treatments for patients are aimed at immunosuppression and immunomodulation (4). Unlike many other PNS, LE is often associated with a favorable response to therapy following surgical removal of the underlying neoplasm accompanied by chemotherapy or immunosuppressive therapy $(54,55)$.

\section{Subacute sensory neuropathy (SSN)}

SSN is a PNS that involves the peripheral nervous system at the level of dorsal root ganglia. Damage to sensory nerves is caused by cell-mediated mechanisms (56). The presence of anti-Hu antibodies is a very strong indication of the presence of an SSN (47). Patients with SSN have a subacute disease course that typically develops over weeks to months. They commonly present with an asymmetric distribution of paresthesias involving all limbs. There is preferential involvement of upper limbs prior to the symptoms emerging in the lower limbs. These paresthesias can be described as painful by patients and are associated with the loss of all sensory modalities. Notably, deep tendon reflexes may remain preserved.

SSN is diagnosed by performing nerve conduction studies. These studies will show a marked difference in the pattern of reduced or absent action potentials in the sensory nerve and preserved motor conduction velocities. Cerebrospinal fluid findings can be used to help differentiate between paraneoplastic SSN and non-neoplastic SSN.
Paraneoplastic SSN will typically have the presence of oligoclonal bands, increased protein concentration and pleocytosis in the cerebrospinal fluid (23). Treatment with immunomodulation and immunosuppressant is usually ineffective and early diagnosis and treatment of the underlying neoplasm is the mainstay of therapy (4).

\section{Cerebellar degeneration}

Cerebellar degeneration associated with neoplasia, referred to as paraneoplastic cerebellar degeneration, was first described in the literature in 1965 and is characterized by the subacute onset of cerebellar dysfunction, including gait difficulty, limb ataxia, dysarthria, dysphagia, nystagmus, and mental status changes (57). Pathologically, loss of Purkinje cells and thinning of the molecular and granular layers of the cerebellum, as well as degeneration of the dentate nuclei, olivary nuclei, and long tracts of the spinal cord are seen on histologic examination. Shortly after this condition was first described, several antibodies were found in the CSF and serum against neuronal proteins that were expressed by the tumor in cancer patients, allowing for further subclassification of this syndrome (2,58-60). With this finding, the onset of cerebellar symptoms can now lead to early diagnosis of the tumor. In regards to SCLC, the most common antibodies present are anti-Hu and antiYo. Anti-Hu antibodies usually indicate a more widespread disorder and sensory neuropathy but are almost always associated with SCLC $(61,62)$. The titers of both the anti$\mathrm{Hu}$ and anti-Yo antibodies can be obtained, however, the levels do not correspond with level of disability or response to therapy. Patients with the anti-Hu antibody typically have extensive inflammatory infiltrates in the nervous system and neuronal degeneration not restricted to the Purkinje cells in the cerebellum, resulting in death from the neurological disorder (61,63-65). Thirteen percent of patients with SCLC and encephalomyelitis present with a subacute cerebellar syndrome that in the initial stages cannot be differentiated from paraneoplastic cerebellar degeneration, suggesting that the Anti-Hu antibody predicts the development of encephalomyelitis (64).

Patients with anti-Hu paraneoplastic cerebellar degeneration also have extracerebellar symptoms, including increased peripheral pain, dementia, muscular weakness, dysphagia, nystagmus, and abnormal reflexes. Frequently seen also is diplopia without ocular paralysis, seen more commonly in patients with anti-Yo associated paraneoplastic cerebellar degeneration $(66,67)$. When paraneoplastic 
cerebellar degeneration is suspected, imaging is obtained with CT and MRI imaging to rule out other neurologic complications of cancer, and to find other structural lesions throughout the body. Cerebellar atrophy, when present, is delayed and occurs months after the neurological symptoms have stabilized $(67,68)$.

The use of steroids, intravenous immunoglobulin, and plasma exchange as treatments have rarely been successful at improving the neurological outcome, as have efforts focusing on controlling the underlying carcinoma. In the majority of cases described, even when the underlying SCLC was controlled, the paraneoplastic cerebellar degeneration continued to worsen or at best remained the same. In other underlying malignancies, however, there are case reports of improvement with control of the tumor and immunomodulating therapy (69-71).

\section{Opsoclonus-myoclonus ataxia (OMA)}

OMA syndrome is a paraneoplastic syndrome classically associated in the literature with neuroblastoma in children and SCLC in adults. It is characterized by involuntary, rapid eye movements without intersaccadic intervals and associated with involuntary multifocal myoclonus affecting the limbs, head, and trunk, as well as cerebellar ataxia. It has also been described with other malignancies, including breast and ovarian carcinomas, as well as thyroid cancer (72). The antibody typically found in the serum and CSF is anti$\mathrm{Ri}$, which is an antibody that targets the enzyme glutamic acid decarboxylase, which is responsible for converting glutamic acid to GABA and when focused, results in cerebellar degeneration and ataxia $(73,74)$. Titers of the anti-Ri antibody can be obtained, however they are not predictive of level of disability or response to therapy.

OMA rarely improves with immunomodulatory agents such as steroids, plasma exchange, or intravenous immunoglobulin (75). The symptoms are due to neuronal damage and the destruction in non-reversible, amounting to the ineffectiveness of the immunomodulatory treatments (76). The best way to prevent further progression of neurologic symptoms is by treating the underlying neoplasm $(75,76)$.

\section{Conclusions}

SCLC is the most common subtype of lung cancer to be associated with paraneoplastic syndromes. Paraneoplastic syndromes in SCLC most frequently involve the endocrine and neurologic systems. The disease process is caused by the ectopic production of biologically active secreted substances and autoimmune-mediated mechanisms. The severity of paraneoplastic disease symptoms is unrelated to the size of the primary tumor, and they can present at any stage of the disease. The presence of these paraneoplastic syndromes in patients with an undiagnosed SCLC offers an opportunity for their early diagnosis and treatment improving their chances of survival. Symptoms in paraneoplastic endocrine syndromes may be reversed with the removal of the underlying tumor. However, in the case of paraneoplastic neurological syndromes, especially in those cases of SCLC associated with the presence of anti-Hu antibodies, removal of the tumor often fails to result in clinical improvement. Despite this, the earliest possible removal and treatment of the cancer remains the mainstay of management in these cases. As we continue to discover new onconeural antibodies in patients with paraneoplastic syndromes, their relationships and clinical implications with different cancers, we will be able improve our understanding and develop effective ways to diagnose and treat our patients. Novel insights into the mechanism by which various paraneoplastic syndromes develop may allow us to discover new opportunities to develop effective targeted therapies for symptoms of paraneoplastic syndromes.

\section{Acknowledgments}

Funding: None.

\section{Footnote}

Provenance and Peer review: This article was commissioned by the Guest Editor (Jose M. Pacheco) for the series "Small Cell Lung Cancer", published in Fournal of Thoracic Disease. This article has undergone external peer review.

Conflicts of Interest: All authors have completed the ICMJE uniform disclosure form (available at http://dx.doi. org/10.21037/jtd.2020.03.88). The series "Small Cell Lung Cancer" was commissioned by the editorial office without any funding or sponsorship. JM reports other from Bayer Pharmaceuticals, outside the submitted work. Other authors have no other conflicts of interest to declare.

Ethical Statement: The authors are accountable for all aspects of the work in ensuring that questions related to the accuracy or integrity of any part of the work are appropriately investigated and resolved. 
Open Access Statement: This is an Open Access article distributed in accordance with the Creative Commons Attribution-NonCommercial-NoDerivs 4.0 International License (CC BY-NC-ND 4.0), which permits the noncommercial replication and distribution of the article with the strict proviso that no changes or edits are made and the original work is properly cited (including links to both the formal publication through the relevant DOI and the license). See: https://creativecommons.org/licenses/by-nc-nd/4.0/.

\section{References}

1. Guichard A, Vignon G. La polyradiculonévrite cancéreuse métastatique; paralysies multiples des nerfs craniens et rachidiens par généralisation microscopique d'un épithélioma du colutérin. J Med Lyon 1949;30:197-207.

2. Graus F, Dalmou J, Rene R, et al. Anti-Hu antibodies in patients with small-cell lung cancer: association with complete response to therapy and improved survival. J Clin Oncol 1997;15:2866-72.

3. Voltz R. Paraneoplastic neurological syndromes: an update on diagnosis, pathogenesis, and therapy. Lancet Neurol 2002;1:294-305.

4. Pelosof LC, Gerber DE. Paraneoplastic Syndromes: An Approach to Diagnosis and Treatment. Mayo Clinic Proceedings 2010;85:838-54.

5. Hauber HP. Paraneoplastic syndromes in lung cancer. Pneumologie 2011;65:347-58.

6. Oppenheim H. Über Hirnsymptome bei Carcinomatose ohne nachweisbare Veränderungen im Gehirn. CharitéAnnalen (Berlin) 1888;13:335-44.

7. Baijens LW, Manni JJ. Paraneoplastic syndromes in patients with primary malignancies of the head and neck. Four cases and a review of the literature. Eur Arch Otorhinolaryngol 2006;263:32-6.

8. Institute NC. Surveillance, Epidemiology, and End Results Program. 2019. Available online: https://seer.cancer.gov/ statfacts/html/lungb.html. Accessed 2/17/2020.

9. Imura H, Matsukura S, Yamamoto H, et al. Studies on ectopic ACTH-producing tumors. II. Clinical and biochemical features of 30 cases. Cancer 1975;35:1430-7.

10. Vanhees SL, Paridaens R, Vansteenkiste JF. Syndrome of inappropriate antidiuretic hormone associated with chemotherapy-induced tumour lysis in small-cell lung cancer: case report and literature review. Ann Oncol 2000;11:1061-5.

11. Tai P, Yu E, Jones K, et al. Syndrome of inappropriate antidiuretic hormone secretion (SIADH) in patients with limited stage small cell lung cancer. Lung Cancer 2006;53:211-5.

12. Kumkum Jha MP. Immunology of lung cancer. World Journal of Pathology 2012;9.

13. Yeung SC, Habra MA, Thosani SN. Lung cancerinduced paraneoplastic syndromes. Curr Opin Pulm Med 2011;17:260-8.

14. Schwartz WB, Bennett W, Curelop S, et al. A syndrome of renal sodium loss and hyponatremia probably resulting from inappropriate secretion of antidiuretic hormone. Am J Med 1957;23:529-42.

15. Wang X, Liu M, Zhang L, et al. Syndrome of Inappropriate Antidiuretic Hormone Secretion: A Poor Prognosis in Small-cell Lung Cancer. Arch Med Res 2016;47:19-24.

16. Flombaum CD. Metabolic emergencies in the cancer patient. Semin Oncol 2000;27:322-34.

17. Vorherr H, Massry SG, Utiger RD, et al. Antidiuretic principle in malignant tumor extracts from patients with inappropriate $\mathrm{ADH}$ syndrome. J Clin Endocrinol Metab 1968;28:162-8.

18. Rami-Porta JR, Bolejack JV, Giroux JD, et al. The IASLC Lung Cancer Staging Project: The New Database to Inform the Eighth Edition of the TNM Classification of Lung Cancer. J Thorac Oncol 2014;9:1618-24.

19. Bernhardt EB, Jalal SI. Small Cell Lung Cancer. In: Reckamp KL, editor. Lung Cancer: Treatment and Research. Cham: Springer International Publishing; 2016:301-22.

20. List AF, Hainsworth JD, Davis BW, et al. The syndrome of inappropriate secretion of antidiuretic hormone (SIADH) in small-cell lung cancer. J Clin Oncol 1986;4:1191-8.

21. Ellison DH, Berl T. Clinical practice. The syndrome of inappropriate antidiuresis. $\mathrm{N}$ Engl J Med 2007;356:2064-72.

22. Reijnders TDY, Janssen WMT, Niamut SML, et al. Role of Risk Factors in Developing Osmotic Demyelination Syndrome During Correction of Hyponatremia: A Case Study. Cureus 2020;12:e6547.

23. Camdessanche JP, Antoine JC, Honnorat J, et al. Paraneoplastic peripheral neuropathy associated with anti$\mathrm{Hu}$ antibodies. A clinical and electrophysiological study of 20 patients. Brain 2002;125:166-75.

24. Sterns RH, Riggs JE, Schochet SS, Jr. Osmotic demyelination syndrome following correction of hyponatremia. N Engl J Med 1986;314:1535-42.

25. Zhang HY, Zhao J. Ectopic Cushing syndrome in small cell lung cancer: A case report and literature review. 
Thorac Cancer 2017;8:114-7.

26. Mayer S, Cypess AM, Kocher ON, et al. Uncommon presentations of some common malignancies: Case 1. Sequential paraneoplastic endocrine syndromes in smallcell lung cancer. J Clin Oncol 2005;23:1312-4.

27. Ilias I, Torpy DJ, Pacak K, et al. Cushing's syndrome due to ectopic corticotropin secretion: twenty years' experience at the National Institutes of Health. J Clin Endocrinol Metab 2005;90:4955-62.

28. Brown WH. A case of Pluriglandular Syndrome: "Diabetes of a bearded women.". Lancet 1928;212:1022-3.

29. Suyama K, Naito Y, Yoh K, et al. Development of Cushing's syndrome during effective chemotherapy for small cell lung cancer. Intern Med 2011;50:335-8.

30. Jeong C, Lee J, Ryu S, et al. A Case of Ectopic Adrenocorticotropic Hormone Syndrome in Small Cell Lung Cancer. Tuberc Respir Dis (Seoul) 2015;78:436-9.

31. Shepherd FA, Laskey J, Evans WK, et al. Cushing's syndrome associated with ectopic corticotropin production and small-cell lung cancer. J Clin Oncol 1992;10:21-7.

32. Hadem J, Cornberg M, Langer F, et al. Making sense of muscle fatigue and liver lesions. Z Gastroenterol 2007;45:609-11.

33. Aoki M, Fujisaka Y, Tokioka S, et al. Small-cell Lung Cancer in a Young Adult Nonsmoking Patient with Ectopic Adrenocorticotropin (ACTH) Production. Intern Med 2016;55:1337-9.

34. Kanaji N, Watanabe N, Kita N, et al. Paraneoplastic syndromes associated with lung cancer. World J Clin Oncol 2014;5:197-223.

35. Shepherd FA, Hoffert B, Evans WK, et al. Ketoconazole. Use in the treatment of ectopic adrenocorticotropic hormone production and Cushing's syndrome in small-cell lung cancer. Arch Intern Med 1985;145:863-4.

36. Dimopoulos MA, Fernandez JF, Samaan NA, et al. Paraneoplastic Cushing's syndrome as an adverse prognostic factor in patients who die early with small cell lung cancer. Cancer 1992;69:66-71.

37. Sarlis NJ, Chanock SJ, Nieman LK. Cortisolemic indices predict severe infections in Cushing syndrome due to ectopic production of adrenocorticotropin. J Clin Endocrinol Metab 2000;85:42-7.

38. Small M, Lowe GD, Forbes CD, et al. Thromboembolic complications in Cushing's syndrome. Clin Endocrinol (Oxf) 1983;19:503-11.

39. Kastelan D, Dusek T, Kraljevic I, et al. Hypercoagulability in Cushing's syndrome: the role of specific haemostatic and fibrinolytic markers. Endocrine 2009;36:70-4.
40. Van Zaane B, Nur E, Squizzato A, et al. Hypercoagulable state in Cushing's syndrome: a systematic review. J Clin Endocrinol Metab 2009;94:2743-50.

41. Graus F, Delattre JY, Antoine JC, et al. Recommended diagnostic criteria for paraneoplastic neurological syndromes. J Neurol Neurosurg Psychiatry 2004;75:1135-40.

42. Honnorat J, Antoine JC. Paraneoplastic neurological syndromes. Orphanet J Rare Dis 2007;2:22.

43. de Beukelaar JW, Smitt PAS. Managing Paraneoplastic Neurological Disorders. Oncologist 2006;11:292-305.

44. Gozzard P, Woodhall M, Chapman C, et al. Paraneoplastic neurologic disorders in small cell lung carcinoma: A prospective study. Neurology 2015;85:235-9.

45. Albert ML, Austin LM, Darnell RB. Detection and treatment of activated $T$ cells in the cerebrospinal fluid of patients with paraneoplastic cerebellar degeneration. Ann Neurol 2000;47:9-17.

46. Didelot A, Honnorat J. Paraneoplastic disorders of the central and peripheral nervous systems. Handb Clin Neurol 2014;121:1159-79.

47. Giometto B, Grisold W, Vitaliani R, et al. Paraneoplastic Neurologic Syndrome in the PNS Euronetwork Database: A European Study From 20 Centers. Arch Neurol 2010;67:330-5.

48. Gandhi L, Johnson BE. Paraneoplastic syndromes associated with small cell lung cancer. J Natl Compr Canc Netw 2006;4:631-8.

49. Titulaer MJ, Lang B, Verschuuren JJ. Lambert-Eaton myasthenic syndrome: from clinical characteristics to therapeutic strategies. Lancet Neurol 2011;10:1098-107.

50. Lennon VA, Kryzer TJ, Griesmann GE, et al. CalciumChannel Antibodies in the Lambert-Eaton Syndrome and Other Paraneoplastic Syndromes. N Engl J Med 1995;332:1467-75.

51. Verschuuren JJ, Wirtz PW, Titulaer MJ, et al. Available treatment options for the management of LambertEaton myasthenic syndrome. Expert Opin Pharmacother 2006;7:1323-36.

52. Shimazaki H, Ando Y, Nakano I, et al. Reversible limbic encephalitis with antibodies against the membranes of neurones of the hippocampus. J Neurol Neurosurg Psychiatry 2007;78:324-5.

53. Didelot A, Honnorat J. Update on paraneoplastic neurological syndromes. Curr Opin Oncol 2009;21:566-72.

54. Ryu JY, Lee SH, Lee EJ, et al. A case of paraneoplastic limbic encephalitis associated with small cell lung cancer. Tuberc Respir Dis (Seoul) 2012;73:273-7. 
55. Lalani N, Haq R. Prognostic effect of early treatment of paraneoplastic limbic encephalitis in a patient with smallcell lung cancer. Curr Oncol 2012;19:e353-7.

56. Camdessanche JP, Jousserand G, Ferraud K, et al. The pattern and diagnostic criteria of sensory neuronopathy: a case-control study. Brain 2009;132:1723-33.

57. Brain L, Wilkinson M. Subacute cerebellar degeneration associated with neoplasms. Brain 1965;88:465-78.

58. Trotter JL, Hendin BA, Osterland CK. Cerebellar degeneration with Hodgkin disease. An immunological study. Arch Neurol 1976;33:660-1.

59. Greenlee JE, Brashear HR. Antibodies to cerebellar Purkinje cells in patients with paraneoplastic cerebellar degeneration and ovarian carcinoma. Ann Neurol 1983;14:609-13.

60. Jaeckle KA, Graus F, Houghton A, et al. Autoimmune response of patients with paraneoplastic cerebellar degeneration to a Purkinje cell cytoplasmic protein antigen. Ann Neurol 1985;18:592-600.

61. Anderson NE, Rosenblum MK, Graus F, et al. Autoantibodies in paraneoplastic syndromes associated with small-cell lung cancer. Neurology 1988;38:1391-8.

62. Dalmau J, Posner JB. Neurological paraneoplastic syndromes. Springer Semin Immunopathol 1996;18:85-95.

63. Graus F, Elkon KB, Lloberes P, et al. Neuronal antinuclear antibody (anti-Hu) in paraneoplastic encephalomyelitis simulating acute polyneuritis. Acta Neurol Scand 1987;75:249-52.

64. Dalmau J, Graus F, Rosenblum MK, et al. Anti-Hu-associated paraneoplastic encephalomyelitis/sensory neuronopathy. A clinical study of 71 patients. Medicine (Baltimore) 1992;71:59-72.

65. Dalmau J, Graus F, Cheung NK, et al. Major histocompatibility proteins, anti-Hu antibodies, and paraneoplastic encephalomyelitis in neuroblastoma and small cell lung cancer. Cancer 1995;75:99-109.

66. Hammack JE, Kimmel DW, O'Neill BP, et al.

Cite this article as: Soomro Z, Youssef M, Yust-Katz S, Jalali A, Patel AJ, Mandel J. Paraneoplastic syndromes in small cell lung cancer. J Thorac Dis 2020;12(10):6253-6263. doi: 10.21037/ jtd.2020.03.88
Paraneoplastic cerebellar degeneration: a clinical comparison of patients with and without Purkinje cell cytoplasmic antibodies. Mayo Clin Proc 1990;65:1423-31.

67. Peterson K, Rosenblum MK, Kotanides H, et al. Paraneoplastic cerebellar degeneration. I. A clinical analysis of 55 anti-Yo antibody-positive patients. Neurology 1992;42:1931-7.

68. Posner JB. Neurologic complications of systemic cancer. Dis Mon 1978;25:1-60.

69. Satoyoshi E, Kowa H, Suzuki Y, et al. Subacute cerebellar degeneration and Eaton-Lambert syndrome associated with lung cancer. Rinsho Shinkeigaku 1973;13:147-55.

70. Paone JF, Jeyasingham K. Remission of cerebellar dysfunction after pneumonectomy for bronchogenic carcinoma. N Engl J Med 1980;302:156.

71. Cocconi G, Ceci G, Juvarra G, et al. Successful treatment of subacute cerebellar degeneration in ovarian carcinoma with plasmapheresis. A case report. Cancer 1985;56:2318-20.

72. Dropcho E, Payne R. Paraneoplastic opsoclonusmyoclonus. Association with medullary thyroid carcinoma and review of the literature. Arch Neurol 1986;43:410-5.

73. Pittock SJ, Lucchinetti CF, Lennon VA. Antineuronal nuclear autoantibody type 2: paraneoplastic accompaniments. Ann Neurol 2003;53:580-7.

74. Bataller L, Rosenfeld MR, Graus F, et al. Autoantigen diversity in the opsoclonus-myoclonus syndrome. Ann Neurol 2003;53:347-53.

75. Keime-Guibert F, Graus F, Fleury A, et al. Treatment of paraneoplastic neurological syndromes with antineuronal antibodies (Anti-Hu, anti-Yo) with a combination of immunoglobulins, cyclophosphamide, and methylprednisolone. J Neurol Neurosurg Psychiatry 2000;68:479-82.

76. Vernino S, O'Neill BP, Marks RS, et al. Immunomodulatory treatment trial for paraneoplastic neurological disorders. Neuro Oncol 2004;6:55-62. 